\title{
A continuous model of biomass size spectra governed by predation and the effects of fishing on them
}

\author{
Eric Benoît ${ }^{\mathrm{a}}$ and Marie-Joëlle Rochet ${ }^{\mathrm{b}_{*}}$
}

\author{
a Laboratoire de Mathématiques, Université de la Rochelle, Avenue Michel Crépeau, 17042, La Rochelle, France \\ b Laboratoire MAERHA, IFREMER, Rue de l'Ile d'Yeu, B.P. 21105, 44311, Nantes Cedex 03, France \\ *mirochet@ifremer.fr Tel.: +33-2-40-37-40-00; fax: +33-2-40-37-40-75
}

\begin{abstract}
A new time-dependent continuous model of biomass size spectra is developed. In this model, predation is the single process governing the energy flow in the ecosystem, as it causes both growth and mortality. The ratio of predator to prey is assumed to be distributed: predators may feed on a range of prey sizes. Under these assumptions, it is shown that linear size spectra are stationary solutions of the model. Exploited fish communities are simulated by adding fishing mortality to the model: it is found that realistic fishing should affect the curvature and stability of the size spectrum rather than its slope.
\end{abstract}

Keywords: Allometry; Biomass size spectrum; Growth; Mortality; Predation 


\title{
A continuous model of biomass size spectra governed by predation, and the effects of fishing on them
}

\author{
Eric Benoît* Marie-Joëlle Rochet ${ }^{\dagger}$
}

\begin{abstract}
A new time-dependent continuous model of biomass size spectra is developed. In this model, predation is the single process governing the energy flow in the ecosystem, as it causes both growth and mortality. The ratio of predator to prey is assumed to be distributed: predators may feed on a range of prey sizes. Under these assumptions, it is shown that linear size spectra are stationary solutions of the model. Exploited fish communities are simulated by adding fishing mortality to the model: it is found that realistic fishing should affect the curvature and stability of the size spectrum rather than its slope.
\end{abstract}

\section{Introduction}

Biomass size spectra, the distribution of biomass across body size classes in a community, have been the subject of continuous interest since the first developments by Sheldon and colleagues [Sheldon et al., 1972, Sheldon et al., 1977]. This is both because it appears to be a very conservative feature of marine communities, and because of the strong appeal of summarising complex communities, comprising numerous species with complex trophic interactions, within a simple plot and one or two numbers such as the slope and intercept of the spectrum.

Biomass size spectra have been widely used both in marine and freshwater ecosystems for estimating production at different trophic levels, especially fish production [Sheldon et al., 1977, Borgman, 1982, Leach et al., 1987, Sprules et al., 1991, Boudreau and Dickie, 1992, Cyr and Peters, 1996], predicting the effects of various human perturbations [Borgman and Whittle, 1983,

${ }^{*}$ Laboratoire de mathématiques, Université de la Rochelle, avenue Michel Crépeau, 17042 LA ROCHELLE, France, email : ebenoit@univ-lr.fr

${ }^{\dagger}$ Laboratoire MAERHA, IFREMER, rue de l'Ile d'Yeu, B.P. 21105, 44311 NANTES Cedex 03, France, email : mjrochet@ifremer.fr 
Cottingham, 1999], and for more basic purposes such as analysing ecosystem structure [Schwinghamer, 1981, Sprules and Munawar, 1986] and dynamics [Denman et al., 1989], or estimating mortality rates [Peterson and Wroblewski, 1984]. Moreover, there is growing concern that fisheries management should consider ecosystems rather than individual populations, and biomass size spectra are considered a potentially powerful tool for assessing human impacts on exploited aquatic communities [Kerr and Dickie, 2001, Caddy and Mahon, 1996]. Pioneering works suggested that size spectra are regular and conservative within a fishery, but vary between systems [Pope and Knights, 1982, Murawski and Idoine, 1992]. These variations may be ascribed to fishing. Several authors have hypothesised that exploitation should decrease the slope of a fish community biomass size spectrum, and reported decreasing trends of this slope in exploited systems [Pope et al., 1988, Anonymous, 1995, Greenstreet and Hall, 1996, Anonymous, 1996, Rice and Gislason, 1996], although this pattern is not consistent across all systems [Bianchi et al., 2000].

These studies are mainly based on empirical observations. However, an underlying theory is needed to be fully able to predict and assess the effect of fishing on the size spectrum, and also to determine reference points (how steep should the size spectrum be or not be ?). This theory should also explain why size spectra are regular.

Existing theories of biomass size spectra rely on the flow of biomass from the smallest- to the largest-sized organisms through size-dependent processes. Some of them consider discrete trophic levels and the processes considered include growth, production, respiration, predation and even reproduction [Kerr, 1974, Borgman, 1982, Borgman, 1983, Thiebaux and Dickie, 1992, Thiebaux and Dickie, 1993]. However, applying them to real situations is complicated by the problem of defining trophic levels [Borgman, 1982]. A continuous biomass flow model avoiding this difficulty has been developed [Platt and Denman, 1978, Silvert and Platt, 1978]. In this model, the sizedependent processes governing the energy flow in the ecosystem are loss (mainly by respiration), and a "generalised growth function", which implicitly includes growth and predation. However, to predict the effect of additional mortality on a large community encompassing several size scales, it is desirable to explicitly describe predation processes. Silvert and Platt [Silvert and Platt, 1980] developed a continuous, time-dependent, non-linear model of the size spectrum where the energy flow is governed only by predation, and the associated growth and 
mortality. They predicted that biomass size spectra can be linear, assuming a fixed prey-predator size ratio.

In this paper, this assumption is relaxed and a continuous model of the size spectrum is developed, where the energy flow is governed by predation, with a distributed prey-predator size ratio. This means that predators may feed not only on preys of a given unique size, but on a range of prey sizes. In this model, reproduction is assumed constant and independent of the biomass present in the system. We first develop the model and establish some of its mathematical properties: it is predicted that size-spectra can still be linear ; other ecological consequences of the model are also examined to appraise the consistency and realism of the assumptions. We then perform some numerical simulations to predict the effect of fishing on a fish community. The model is developed for fish in the broad meaning of "animals swimming and foraging in the open water".

\section{The model}

\section{$2.1 \quad$ Notations}

\begin{tabular}{|c||l|c|}
\hline Symbol & \multicolumn{1}{|c|}{ Definition } & Unit \\
\hline \hline$w$ & weight of a fish & $g$ \\
\hline$x$ & logarithm of $w$ & $\ln (g)$ \\
\hline$t$ & time & year $=y$ \\
\hline$u(x, t)$ & $\begin{array}{l}\text { number of fishes at time } t \text { by unit volume, by unit of } \\
\text { x }\end{array}$ & $m^{-3}$ \\
\hline $\int_{x_{1}}^{x_{2}} u(x, t) d x$ & $\begin{array}{l}\text { number of fishes with weight in }\left[e^{x_{1}}, e^{x_{2}}\right], \text { at time } t, \\
\text { by unit volume }\end{array}$ & $m^{-3}$ \\
\hline$g(x, t)$ & growth rate & $y^{-1}$ \\
\hline$\mu(x, t)$ & mortality rate & $y^{-1}$ \\
\hline$\varphi(q)$ & $\begin{array}{l}\text { probability of predation when a predator size } x \\
\text { meets a prey size } x-q\end{array}$ \\
\hline
\end{tabular}

Table 1: Definition of the mathematical variables

The fundamental independent variables are time $t$ and $x$, where $x$ is the (natural) logarithm of the weight $w$ of a fish. The derivative with respect to $x$ is related to the derivative with respect to $w$ by

$$
\frac{\partial}{\partial x}=w \frac{\partial}{\partial w}
$$


The fundamental unknown is $u(x, t)$, the distribution of the number of fish with respect to $x$. Then, the number of fish in the weight range $\left[w_{1}, w_{2}\right]$ is given by the formula

$$
\int_{\ln w_{1}}^{\ln w_{2}} u(x, t) d x
$$

The mathematical change of variable $x=\ln w$ shows that this expression is equivalent to

$$
\int_{w_{1}}^{w_{2}} \frac{1}{w} u(\ln (w), t) d w
$$

The mass of a fish is $w=e^{x}$, so the biomass of all fish in the weight range $\left[w_{1}, w_{2}\right]$ is given by

$$
\int_{x_{1}}^{x_{2}} e^{x} u(x, t) d x \quad \text { or, equivalently } \int_{w_{1}}^{w_{2}} u(\ln (w), t) d w
$$

The function $u$ can be considered either as the distribution in $x$ of the number of fish or as the distribution in $w$ of the biomass.

Consider a fish of weight $W(t)$, and $X(t)=\ln (W(t))$. The growth function $g$ is given by

$$
\frac{d X}{d t}=g(X(t), t)
$$

or, using weight,

$$
\frac{d W}{d t}=W(t) g(\ln (W(t)), t)
$$

The function $\mu(x, t)$ is the mortality rate of fish at weight $e^{x}$.

\subsection{Balance}

At time $t$, the number of fish in the weight range $\left[e^{x_{1}}, e^{x_{2}}\right]$ is given by

$$
\int_{x_{1}}^{x_{2}} u(x, t) d x
$$

Some fish die and at time $t+d t$, the remaining number of fish is

$$
\int_{x_{1}}^{x_{2}}(1-\mu(x, t) d t) u(x, t) d x
$$

Because, in the same time, they grow, these remaining fish are exactly the fish in the weight range $\left[e^{x_{1}+g\left(x_{1}, t\right) d t}, e^{x_{2}+g\left(x_{2}, t\right) d t}\right]$ at time $t+d t$. This number is

$$
\int_{x_{1}+g\left(x_{1}, t\right) d t}^{x_{2}+g\left(x_{2}, t\right) d t} u(x, t+d t) d x
$$


We equate these numbers and compute the derivative with respect to $d t$ at the value $d t=0$ :

$$
-\int_{x_{1}}^{x_{2}} \mu(x, t) u(x, t) d x=\int_{x_{1}}^{x_{2}} \frac{\partial u}{\partial t}(x, t) d x+g\left(x_{2}, t\right) u\left(x_{2}, t\right)-g\left(x_{1}, t\right) u\left(x_{1}, t\right)
$$

Derive with respect to $x_{2}$ :

$$
\frac{\partial u}{\partial t}=-\frac{\partial(g u)}{\partial x}-\mu u
$$

This equation is well known in hydrodynamics (mass-balance in a transport equation) and in population dynamics (see [Silvert and Platt, 1978, Silvert and Platt, 1980] and Mc Kendrick-von Foerster equation, see e.g. [Kot, 2001]).

\subsection{Predation}

In this model, predation is the unique driving force of growth and mortality. Each predation event implies two individuals. One (with weight $e^{y}$ ) will grow, the other (with weight $e^{x}$ ) will die. The ratio of the weights of the two individuals is supposed to be distributed independently of the weights of the individuals: when two individuals of weights $e^{x}$ and $e^{y}$ meet, the probability that a predation happens is given by a function $\varphi$ which depends only on the ratio of the weights $e^{y-x}$. We denote $y-x$ by $q$. The function $\varphi$ (figure 2.3) is chosen domeshaped, positive, having a unique maximum which implies an effective search for a preferred prey size. Because preys are generally smaller than predators, the function $\varphi$ is almost zero for negative values of $q$. But we do not need that $\varphi$ is exactly zero for negative $q$. For numerical simulations, we take :

$$
\varphi(q)=\left\{\begin{array}{lll}
e^{n}\left(\frac{q}{q_{0}}\right)^{n} e^{-n \frac{q}{q_{0}}} & \text { if } & q \geq 0 \\
0 & \text { if } & q \leq 0
\end{array}\right.
$$

This function $\varphi$ peaks at 1 for $q_{0}$. The parameter $n$ determines the width of the peak of $\varphi$.

Let us consider a predator of weight $e^{y}$ in a period of time $d t$. The volume searched is supposed to be an allometric function of weight: it is given by $A e^{\alpha y} d t$. This allometry was derived by [Ware, 1978] based on considerations about the bioenergetics of fish. Then the number of encounters with possible preys of weight in $\left[e^{x}, e^{x+d x}\right]$ is $A e^{\alpha y} u(x, t) d t d x$. The number of preys eaten in the weight range $\left[e^{x}, e^{x+d x}\right]$ is $A e^{\alpha y} \varphi(y-x) u(x, t) d t d x$. The distribution of predation events is given by

$$
A e^{\alpha y} \varphi(y-x) u(x, t) u(y, t) d x d y d t
$$




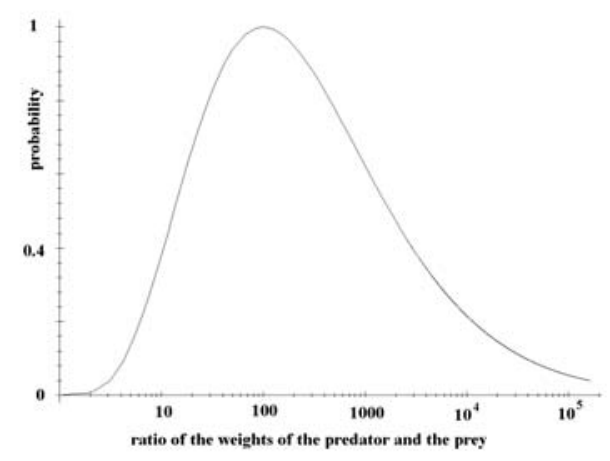

Figure 1: Graph of $\varphi$, the probability that a predator of weight $e^{y}$ meeting a prey of weight $e^{y-q}$ will eat it.

\subsection{Mortality}

From the point of view of the prey, expression (6) gives the mortality rate by predation :

$$
\mu(x, t)=\int_{-\infty}^{\infty} A e^{\alpha y} \varphi(y-x) u(y, t) d y
$$

which is equivalent to

$$
\mu(x, t)=A e^{\alpha x} \int_{-\infty}^{\infty} e^{\alpha q} \varphi(q) u(x+q, t) d q
$$

Non predation mortality is accounted for by an additional mortality rate

$$
\mu_{0} e^{\alpha x} u(x, t)
$$

which increases allometrically with body size and also increases with the number of animals in the ecosystem (density-dependence mortality). The allometric coefficient was chosen to allow the mathematical analysis in section 3 .

In simulations, we will add a fishing mortality rate $\mu_{f}(x, t)$.

\subsection{Growth}

From distribution (6), the mass of preys eaten by one predator is :

$$
A e^{\alpha y} d t \int_{-\infty}^{\infty} e^{x} \varphi(y-x) u(x, t) d x
$$


( $e^{x}$ is the weight of one prey).

The increase in weight of the predator is given by $e^{y} g(y, t) d t$ (confer section 2.1 ). If the biomass eaten is used to grow with a constant efficiency $K$, then

$$
g(y, t)=K A e^{\alpha y} \int_{-\infty}^{\infty} e^{-q} \varphi(q) u(y-q, t) d q
$$

\subsection{Conclusion}

Combining equations (4), (7) and (9), we obtain the following model

$$
\begin{aligned}
\frac{\partial u}{\partial t}(x, t)= & -\frac{\partial}{\partial x}\left[K A e^{\alpha x} \int_{-\infty}^{\infty} e^{-q} \varphi(q) u(x-q, t) u(x, t) d q\right] \\
& -A e^{\alpha x} \int_{-\infty}^{\infty} e^{\alpha q} \varphi(q) u(x+q, t) u(x, t) d q \\
& -\mu_{0} e^{\alpha x} u(x, t)^{2}-\mu_{f}(x, t)
\end{aligned}
$$

Equation (10) is an equation of evolution, $\frac{\partial u}{\partial t}=\mathcal{A}(u)$, where $\mathcal{A}$ is an operator on the functions of one variable $x$. The difficulty lies in this operator being not local : it includes convolutions.

\section{Some mathematical properties of the model without fishing}

To allow a mathematical study, we first assume that the solution $u(x, t)$ is defined for all real $x$, i.e., for all positive weights. Actually, it is not realistic: we need another model for lower levels (plankton) in the ecosystem (see section 5.4).

For the sake of generality, $\varphi$ is kept as a parameter-function. Let $D_{\varphi}$ be the set of real numbers $\ell$ such that the integral $\int_{-\infty}^{\infty} \varphi(q) e^{\ell q} d q$ is convergent. For the explicit $\varphi$ given above, $D_{\varphi}=\left(-\infty, n / q_{0}\right)$; if $\varphi$ has a compact support, $D_{\varphi}=(-\infty,+\infty)$.

\subsection{Relationship between rate and concentration}

As the operator $\mathcal{A}$ is homogeneous quadratic with respect to $u$, the following lemma is obvious :

Lemma 1 If $u(x, t)$ is a solution of the model, and if $c$ is a constant, then, $c u(x, c t)$ is also a solution of the model. 
The biological meaning of this lemma is : if the concentration of fish, biomass and nutrients is multiplied by a constant factor $c$, the biomass dynamics will be similar, at a rate multiplied by $c$, consistently with the findings by [Silvert and Platt, 1980] for a fixed prey-predator size ratio. Another consequence of this lemma is that if we change the parameter $A$ to $c A$ and $\mu_{0}$ to $c \mu_{0}$, the solution $u(x, t)$ becomes $u(x, t / A)$, or $A u(x, t)$. Then, the parameters $A$ and $u_{0}$ do not influence the qualitative behaviour of the model, they determine only the rate of biomass flow.

\subsection{Stationary linear spectrum}

Lemma 2 If $\varphi(q)$ is zero for negative values of $q$, there exists a unique real $\lambda$ such that for any $u_{0}$, the function $u(x, t)=u_{0} e^{\lambda x}$ is a solution of equation (10). This $\lambda$ is the unique real solution of

$$
(2 \lambda+\alpha) K \int_{-\infty}^{\infty} e^{-(\lambda+1) q} \varphi(q) d q+\int_{-\infty}^{\infty} e^{(\alpha+\lambda) q} \varphi(q) d q+\frac{\mu_{0}}{A}=0
$$

Moreover, $\lambda<-\alpha / 2$.

Proof The proof that a function $e^{\lambda x}$ is a solution of the model if and only if condition (11) is satisfied is easy.

To prove the existence and unicity of $\lambda$, we study the function

$$
F(\lambda)=(2 \lambda+\alpha) K \int_{-\infty}^{\infty} e^{-(\lambda+1) q} \varphi(q) d q+\int_{-\infty}^{\infty} e^{(\alpha+\lambda) q} \varphi(q) d q+\frac{\mu_{0}}{A} .
$$

With the hypothesis on $\varphi$, the domain $D_{\varphi}$ has no lower bound. We can then prove that

- the domain of $F$ is

$$
\left\{\lambda \text { such that }-1-\lambda \in D_{\varphi} \text { and } \alpha+\lambda \in D_{\varphi}\right\}
$$

and it contains $(-\infty,-\alpha / 2)$,

- for $\lambda \geq-\alpha / 2$, the function $F$ is nonnegative,

- the derivative $F^{\prime}(\lambda)$ is positive for all $\lambda<-\alpha / 2$,

- when $\lambda$ decreases towards $-\infty$ the second integral in $F$ goes to 0 , and $F$ goes to $-\infty$.

From this follow the existence and unicity of a real solution of $F(\lambda)=-\mu_{0} / A$, because $-\mu 0 / A<0$. 
When $\varphi$ takes positive values for some negative $q$ (when small predators can eat large preys) the lemma above is not valid (the sign of $F^{\prime}(\lambda)$ becomes not obvious). In some cases, $F$ can have a global negative minimum, so both existence and unicity can be wrong. For example, it is the case for

$$
\varphi(q)=\left\{\begin{array}{lll}
q \exp (-q) & \text { if } & q>0 \\
1 / 10|q| \exp (-q) & \text { if } & q<0
\end{array} .\right.
$$

Although this is not the only solution (nor the only stationary solution : see below), lemma 2 shows that a linearly decreasing size spectrum can appear, even if the predators are allowed to prey on a weight range rather than a single weight, and whatever the shape of the predator-prey size ratio distribution.

\subsection{Other special solutions}

\subsubsection{Weak slope}

Be $C$ the constant

$$
C=\mu_{0}+A \int_{-\infty}^{+\infty}\left(1-\alpha K e^{-(1-\alpha) q}\right) \varphi(q) d q
$$

(assuming that $0 \in D_{\varphi}$ and $\alpha-1 \in D_{\varphi}$ the integral is convergent). If both $\alpha<1, K<1$, and the probability of eating large preys is negligible, then $C>0$. It is easy to show that

$$
u(x, t)=\frac{u_{0} e^{-\alpha x}}{1+C u_{0} t}
$$

is a solution of equation (10) with $u(0,0)=u_{0}$.

Because $C$ is positive, the solution is decreasing towards zero. It is a linear spectrum with a slope weaker than the stationary solution. This means that if for any reason the slope of the spectrum becomes less steep (i.e., more large fish and less small fish), there is a risk of all biomass being washed out of the system by predators eating preys faster than they are created by growth. Only the input from the boundary condition (recruitment) can keep some biomass in the ecosystem. This solution can appear unrealistic, but would it happen, it would be transient and hence not easy to observe.

If $C$ is negative, the slope will be greater than the slope of the stationary solution, and the population will increase indefinitely and tend towards infinity. This solution is mathematically correct, but the input of biomass in the small weights must also increase towards infinity. 


\subsubsection{Gaps in the spectrum}

Let us assume (for this section) that the function $\varphi$ has a compact support, i.e., $\varphi(q)$ is zero except for $q$ in some positive range $\left[q_{m}, q_{M}\right]$. In this case, if $u(0, x)$ is a function which is zero except on some intervals of length less than $q_{m}$ and with gaps of length at least $q_{M}$, then the solution of the system is

$$
u(t, x)=\frac{u(0, x)}{1+\mu_{0} e^{\alpha x} t u(0, x)} .
$$

It corresponds to size spectra where no predation, hence no growth, can occur, because the weights of the fish do not match predators requirements. The only process ongoing is mortality due to the term $\mu_{0} e^{\alpha x} u^{2}$.

\subsection{Total biomass}

The total biomass in one cubic meter is :

$$
B(t)=\int_{-\infty}^{+\infty} e^{x} u(x, t) d x
$$

This integral is divergent, but from an ecological point of view it is not a problem: there is a maximum and a minimum size in any ecosystem. When the density $u$ is given by $u_{0} e^{-x}$ for $x$ belonging to some range $\left[x_{\min }, x_{\max }\right]$ (it is almost the case for the stationary solution computed above), the biomass of fish of weight $w$ in $\left[w_{0}, 2 w_{0}\right]$ is $u_{0} \ln 2$, independent of $w_{0}$ : the biomass is homogeneous with respect to the weight of fish. When $u=e^{\lambda x}$, with $\lambda<-1$, the concentration is higher in small weights.

For a spectrum $u$ which is zero outside a bounded interval, we can compute the variation of the biomass. Using equation (10) :

$$
\begin{gathered}
\frac{d B}{d t}=\int_{-\infty}^{+\infty} e^{x} \frac{\partial u}{\partial t}(x, t) d x= \\
=-\int_{-\infty}^{+\infty}\left[e^{x} \frac{\partial}{\partial x}\left(K A e^{\alpha x} I_{1}\right)+A e^{x} e^{\alpha x} I_{2}+\mu_{0} e^{(\alpha+1) x} u(x, t)^{2}\right] d x
\end{gathered}
$$

with

$$
\begin{aligned}
& I_{1}=\int_{-\infty}^{\infty} e^{-q} \varphi(q) u(x-q, t) u(x, t) d q \\
& I_{2}=\int_{-\infty}^{\infty} e^{\alpha q} \varphi(q) u(x+q, t) u(x, t) d q
\end{aligned}
$$

Integrating by parts, using $u( \pm \infty, t)=0$, we obtain

$$
\frac{d B}{d t}=\int_{-\infty}^{+\infty}\left[e^{x} K A e^{\alpha x} I_{1}-A e^{x} e^{\alpha x} I_{2}-\mu_{0} e^{(\alpha+1) x} u(x, t)^{2}\right] d x
$$


Changing $x$ to $y-q$ in the integral $\int e^{x} e^{\alpha x} I_{2} d x$ gives

$\iint e^{(\alpha+1) x} e^{\alpha q} \varphi(q) u(x+q, t) u(x, t) d q d x=\iint e^{(\alpha+1)(y-q)} e^{\alpha q} \varphi(q) u(y, t) u(y-q, t) d q d y$

Then we conclude that

$$
\begin{gathered}
\frac{d B}{d t}=-A(1-K) \int_{-\infty}^{\infty} \int_{-\infty}^{\infty} e^{(1+\alpha) y} e^{-q} \varphi(q) u(y-q, t) u(y, t) d q d y- \\
-\mu_{0} \int e^{(\alpha+1) x} u(x, t)^{2} d x
\end{gathered}
$$

From this result, it follows that, if $K=1$ and $\mu_{0}=0$, total biomass is invariant. This is a corollary of the model : if $K=1$, the biomass is conservative for each individual predation event. In fact, there are losses when converting food into body mass, hence $K<1$ and the biomass decreases with time. To avoid that, an external input of biomass in the small weights is needed : it is given by small fish food (e.g. plankton). This is related to the boundary condition for small $x$.

\subsection{Individual life history}

Here we give some consequences of the model for an individual fish: its growth curve, life expectancy (average time the fish will live, given it is alive at time $t$ ), and food ration. All this quantities can be computed for an individual fish in a given environment $u(x, t)$. We first assume that this environment is a solution of equation (10); then we make effective computations for the stationay solution of equation (10).

We already defined the growth function $X(t)$ of an individual fish (equation (3)). Combining with $g$ (equation (9)), this gives a differential equation for $X(t)$ which can be solved with the initial condition $X(0)=x_{0}$. It gives the weight $W(t)=e^{X(t)}$ as a function of time.

The food ration or instant amount of prey ingested is given by equation (8).

Equation (7) gives the function $m(t)=\mu(X(t), t)+\mu_{0} e^{\alpha X(t)} u(X(t), t)$ which is the mortality rate at time $t$ for the individual fish. The probability of living until time $t$ for a fish is given by $\exp \int_{0}^{t}-m(\tau) d \tau$.

The distribution of the random variable "age of death" is given by $p(t)=$ $m(t) \exp \left(\int_{0}^{t}-m(\tau) d \tau\right)$.

Then classical formulae give the life expectancy : $E\left(x_{0}\right)=\int_{0}^{\infty} t p(t) d t$. An integration by parts makes the computation easier :

$$
E\left(x_{0}\right)=\int_{0}^{\infty} \exp \left(-\int_{0}^{t} m(\tau) d \tau\right) d t
$$


Let us apply this to compute the life expectancy in the case of the stationary exponential solution $u(x, t)=u_{0} e^{\lambda x}$. Following the procedure above, equation (9) gives:

$$
\begin{gathered}
g(x, t)=K A C_{1} u_{0} e^{(\alpha+\lambda) x} \\
\text { where } \quad C_{1}=\int_{-\infty}^{\infty} e^{-(\lambda+1) q} \varphi(q) d q
\end{gathered}
$$

Equation (3) is now:

$$
\frac{d X}{d t}=K A C_{1} u_{0} e^{(\alpha+\lambda) X(t)}
$$

and we can compute the solution with initial condition $x_{0}$ :

$$
\begin{gathered}
X(t)=-\frac{\ln \left(-C_{1} K A u_{0}(\alpha+\lambda) t+e^{-x_{0}(\alpha+\lambda)}\right)}{\alpha+\lambda} \\
W(t)=\left(-C_{1} K A u_{0}(\alpha+\lambda) t+W_{0}^{-(\alpha+\lambda)}\right)^{-1 /(\alpha+\lambda)}
\end{gathered}
$$

The mortality rate at time $t$ for a fish of weight $W(t)$ is given by equation (7)

$$
\begin{gathered}
m(t)=\frac{C_{3}}{C_{4} t+C_{0}} \\
\text { where } \quad C_{3}=A C_{2} u_{0} \quad C_{4}=K A C_{1} u_{0}(-\alpha-\lambda) \quad C_{0}=W_{0}^{-(\alpha+\lambda)} \\
\text { and } \quad C_{2}=\frac{\mu_{0}}{A}+\int_{-\infty}^{\infty} e^{(\alpha+\lambda) q} \varphi(q) d q
\end{gathered}
$$

Then, the life expectancy for a fish of weight $W_{0}$ is:

$$
E\left(W_{0}\right)=\frac{C_{0}}{C_{3}-C_{4}}
$$

It is easy to check that $C_{3}>C_{4}$ if we remember that $\lambda$ is a solution of equation (11).

\section{Parameters}

For numerical analyses below, we used values of the parameters based on published literature (table 2). The parameters of the model are broad features of a food web and cannot be measured for a given community ; rather, the values in table 2 are reasonable, given the published knowledge on marine organisms and food webs. Both experimental and theoretical sources are reported, as previous theoretical studies performed valuable compilations of former experimental results. 
The value of $\mu_{0}$ is set such that the non-predation mortality rate for a $500 \mathrm{~g}$ fish is 0.2 , an assumption in the range of residual mortality rates usually assumed in multispecies models e.g. for the North Sea and Baltic Sea (0.1-0.2) [Gislason and Helgason, 1985, Gislason, 1999, Anonymous, 2002, Andersen and Ursin, 1977].

\begin{tabular}{|c|c|c|c|c|c|c|c|}
\hline $\begin{array}{l}\text { Para- } \\
\text { meter }\end{array}$ & Definition & $\begin{array}{l}\text { see } \\
\S\end{array}$ & Unit & $\begin{array}{l}\text { Ref. } \\
\text { value }\end{array}$ & $\begin{array}{l}\text { Lower } \\
\text { limit }\end{array}$ & $\begin{array}{l}\text { Upper } \\
\text { limit }\end{array}$ & Sources \\
\hline$\alpha$ & $\begin{array}{l}\text { Exponent of weight } \\
\text { in volume of water } \\
\text { searched }\end{array}$ & 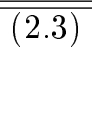 & - & $\overline{0.82}$ & 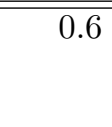 & $\overline{0.9}$ & [Ware, 1978] \\
\hline $\mathrm{A}$ & $\begin{array}{l}\text { Volume searched by } \\
\text { unit weight }\end{array}$ & $(2.3)$ & $m^{3} \cdot y^{-1}$ & 640 & & & [Ware, 1978] \\
\hline$e^{q_{0}}$ & $\begin{array}{lrr}\text { Modal ratio } & \text { of } \\
\text { predator } & \text { size } & \text { to } \\
\text { prey size } & & \end{array}$ & $(2.3)$ & - & 100 & 10 & 1000 & $\begin{array}{l}{[\text { Daan, 1973, Ware, 1978, }} \\
\text { Silvert and Platt, 1980, } \\
\text { Borgman, 1982, } \\
\text { Cohen et al., 1993, } \\
\text { Thiebaux and Dickie, 1993, } \\
\text { Vignes, 1998] }\end{array}$ \\
\hline$n$ & $\begin{array}{l}\text { An inverse measure } \\
\text { of the width of the } \\
\text { predator-prey size } \\
\text { ratio distribution }\end{array}$ & $(2.3)$ & - & 5 & 1 & 10 & $\begin{array}{l}\text { guessed from the distri- } \\
\text { bution of prey size in } \\
\text { predator } \\
\text { [Daan, 1973, }\end{array}$ \\
\hline$K$ & Growth efficiency & $(2.5)$ & - & 0.2 & 0.1 & 0.6 & $\begin{array}{l}\text { [Paloheimo and Dickie, 1966, } \\
\text { Ware, 1978, Borgman, 1982, } \\
\text { Gurney et al., 1990, } \\
\text { Buckel et al., 1995] }\end{array}$ \\
\hline$\mu_{0}$ & $\begin{array}{l}\text { natural mortality } \\
\text { rate }\end{array}$ & $(2.4)$ & $m^{3} \cdot y^{-1}$ & 80 & 0 & 200 & $\begin{array}{l}\text { [Gislason and Helgason, 1985, } \\
\text { Gislason, 1999, } \\
\text { Anonymous, 2002, } \\
\text { Andersen and Ursin, 1977] }\end{array}$ \\
\hline
\end{tabular}

Table 2: Values of the parameters used in model simulations. Lower and higher limits refer to the range of values used in the sensitivity analysis.

\section{$5 \quad$ Numerical simulations}

\subsection{Slope of the stationary solution}

The slope $\lambda$ of the stationary size spectrum was computed from equation (11) with function $\varphi$ given by (5), for different values of the parameters (table 3 ).

The slope of the size spectrum is not sensitive to individual variations in the parameters, especially the width of the predator-prey size ratio distribution. 


\begin{tabular}{|c|c|c|c|c||c|}
\hline$n$ & $e^{q_{0}}$ & $\alpha$ & $K$ & $\mu_{0}$ & $\lambda$ \\
\hline \hline 5 & 100 & 0.82 & 0.2 & 80 & -1.0500 \\
\hline $\mathbf{1 0}$ & 100 & 0.82 & 0.2 & 80 & -1.0589 \\
$\mathbf{1}$ & 100 & 0.82 & 0.2 & 80 & -1.0117 \\
5 & $\mathbf{1 0 0 0}$ & 0.82 & 0.2 & 80 & -1.0105 \\
5 & $\mathbf{1 0}$ & 0.82 & 0.2 & 80 & -1.1569 \\
5 & 100 & $\mathbf{0 . 6}$ & 0.2 & 80 & -0.9558 \\
5 & 100 & $\mathbf{0 . 9}$ & 0.2 & 80 & -1.0847 \\
5 & 100 & 0.82 & $\mathbf{0 . 1}$ & 80 & -1.1099 \\
5 & 100 & 0.82 & $\mathbf{0 . 6}$ & 80 & -0.9560 \\
5 & 100 & 0.82 & 0.2 & $\mathbf{0}$ & -1.0439 \\
5 & 100 & 0.82 & 0.2 & $\mathbf{2 0 0}$ & -1.0589 \\
\hline $\mathbf{1 0}$ & $\mathbf{1 0}$ & $\mathbf{0 . 9}$ & $\mathbf{0 . 1}$ & $\mathbf{2 0 0}$ & -1.3710 \\
$\mathbf{1 0}$ & $\mathbf{1 0 0 0}$ & $\mathbf{0 . 6}$ & $\mathbf{0 . 6}$ & $\mathbf{0}$ & -0.8376 \\
\hline
\end{tabular}

Table 3: Numerical computation of the stationary slope $\lambda$

Predators eating larger preys, searching in volumes increasing steeper with size, and having a lower growth efficiency result in steeper spectra than the opposite settings. A higher non predation residual mortality rate also results in a steeper slope. Keeping all but one of the parameters to their reference value results in slopes of approximately -1 , which is consistent with published data:

- slopes of $\log$ numbers versus log length class ranging from -4 to -10 for weakly to heavily exploited fish communities [Anonymous, 1996, Rice and Gislason, 1996, Bianchi et al., 2000]. Indeed, assuming that body weight is related to body length by $w \propto L^{3}$, the slope $\lambda$ of the density of fish with respect to log weight is related to the slope $\sigma$ of the $\log$ density of fish with respect to length by $3 \lambda=\sigma+1$.

- the slope of $\log$ biomass density versus $\log$ body mass in various aquatic ecosystems being very close to 0 [Boudreau and Dickie, 1992].

- the slope of normalized biomass spectra (log biomass per range of weight classes versus $\log$ weight) being close to -1 or steeper in various plankton communities as well as in benthic fish assemblages in the Benguela System [Macpherson and Gordoa, 1996, Zhou and Huntley, 1997].

Simultaneous changes in the parameters result in wider variations in the slope. However, combining extreme values of all parameters still results in consistently slowly decaying size spectra. The reference value $\lambda=-1.0500$ was 
taken for the simulations below.

\subsection{Initial intercept of the spectrum}

The intercept $u_{0}$ of the biomass spectrum at time $t=0$ was estimated from average densities estimated from published size spectra (table 4). Fish densities are usually estimated from trawl surveys and reported in numbers or biomass per swept area, i.e. per $\mathrm{m}^{2}$. Trawls usually have a vertical opening of a few meters, but considering that most fish are found close to the bottom, the density per $\mathrm{m}^{2}$ can be considered very similar to the density in the first meter of the water column, i.e. per $\mathrm{m}^{3}$. The estimated intercepts vary by three orders of magnitude, depending on ecosystems : it is determined both by primary production and food web structure [Sprules et al., 1991, Cyr and Peters, 1996].

For the stationary linear spectrum, the abundance of fish with weight in $\left[w_{1}, w_{2}\right]$ or length in $\left[L_{1}, L_{2}\right]$ is given by formula (1) i.e., assuming that $w=$ $0.005 L^{3}$

$$
u_{0}\left(\frac{w_{2}{ }^{\lambda}}{\lambda}-\frac{w_{1}^{\lambda}}{\lambda}\right)=0.005^{\lambda} u_{0}\left(\frac{L_{2}{ }^{3 \lambda}}{\lambda}-\frac{L_{1}^{3 \lambda}}{\lambda}\right)
$$

and the biomass is given by formula (2) i.e.

$$
u_{0}\left(\frac{w_{2}{ }^{\lambda+1}}{\lambda+1}-\frac{w_{1}{ }^{\lambda+1}}{\lambda+1}\right)=0.005^{\lambda+1} u_{0}\left(\frac{L_{2}{ }^{3 \lambda+3}}{\lambda+1}-\frac{L_{1}{ }^{3 \lambda+3}}{\lambda+1}\right)
$$

Assuming that the values of the parameters are the reference values (hence $\lambda=-1.0500$ ), $u_{0}$ was computed for each observation (table 4 ).

\begin{tabular}{|l|l|l|c|c|c|c||c|}
\hline Spectrum & Ecosystem & Source & \multicolumn{2}{|c|}{ Size range } & \multicolumn{2}{|c|}{ Density } & $\begin{array}{l}\text { Estimated } \\
\text { intercept }\end{array}$ \\
\hline & & & $\begin{array}{c}\text { Length } \\
(\mathrm{cm})\end{array}$ & $\begin{array}{c}\text { Weight } \\
(\mathrm{g})\end{array}$ & $\begin{array}{c}\text { Number } \\
\left(\mathrm{fish} \mathrm{m}^{-2}\right)\end{array}$ & $\begin{array}{c}\text { Biomass } \\
\left(\mathrm{g} \mathrm{m}^{-2}\right)\end{array}$ & $\left(\mathrm{g} \mathrm{m}^{-3}\right)$ \\
\hline \hline $\begin{array}{l}\text { Demersal } \\
\text { fish }\end{array}$ & $\begin{array}{l}\text { Mediterranean } \\
\text { Sea }\end{array}$ & [Rochet and Lembo, 2003 & $1-100$ & & 0.5 & & 0.002 \\
\hline All fish & Lakes & [Cyr and Peters, 1996] & & $0.2-790$ & & 1 & 0.14 \\
\hline $\begin{array}{l}\text { Planktivorous } \\
\text { fish }\end{array}$ & $\begin{array}{l}\text { Lake Michi- } \\
\text { gan }\end{array}$ & [Sprules et al., 1991] & $5-20$ & & & 6 & 1.56 \\
\hline $\begin{array}{l}\text { Piscivorous } \\
\text { fish }\end{array}$ & $\begin{array}{l}\text { Lake Michi- } \\
\text { gan }\end{array}$ & [Sprules et al., 1991] & $30-80$ & & & 0.2 & 0.09 \\
\hline
\end{tabular}

Table 4: $\quad$ Intercepts estimated from published size spectra.

For all simulations below, $u_{0}=0.01$ was taken as reference value. 


\subsection{Individual life history}

The life history of a hypothetical individual fish with initial weight $W(0)=$ $10^{-3} \mathrm{~g}$ was estimated in terms of growth, annual food ration and life expectancy (Table 5). The predicted growth and life expectancy were checked against the data in [Pauly, 1980], who compiled the parameters of the von Bertalanffy growth model and natural mortality rate estimates for 175 fish species encompassing a wide range of taxonomic groups and environmental conditions. We partitioned the species into 10 groups of increasing natural mortality rate. Based on the growth parameters, the weight at age for each group was then computed, as well as the life expectancy for fish near their asymptotic weight. The growth curves compare satisfactorily, except in ages below one year (Figure 2). This is partly due to the von Bertalanffy growth model not being appropriate to describe early growth of fish. Similarly, the life expectancy predicted by the model fits rather well the data for large fish, but overestimates it in small sizes. This is due to small fish in the model being a mix of small short-lived adult fish and young longer-lived animals. Furthermore, the food ration estimated by the model is consistent with the range of published data, from $30-70 \%$ of the body weight daily for fish larvae [Pepin and Penney, 2000] to $1-7 \%$ for adult fish of various species [Gislason and Helgason, 1985, Daan, 1973, Essington et al., 2001]. Hence the model individual fish seem to have a reasonable life history.

\begin{tabular}{|c||c|c|c|c|c|c|}
\hline Weight & $1 \mathrm{mg}$ & $1 \mathrm{~g}$ & $10 \mathrm{~g}$ & $100 \mathrm{~g}$ & $1 \mathrm{~kg}$ & $10 \mathrm{~kg}$ \\
\hline Age (from weight 1mg) & 0 & $142 \mathrm{~d}$ & $266 \mathrm{~d}$ & $1 \mathrm{y} 112 \mathrm{~d}$ & $2 \mathrm{y} 106 \mathrm{~d}$ & $3 \mathrm{y} 349 \mathrm{~d}$ \\
\hline Annual food ration & $0.22 \mathrm{~g}$ & $45 \mathrm{~g}$ & $262 \mathrm{~g}$ & $1.55 \mathrm{~kg}$ & $9.10 \mathrm{~kg}$ & $53.6 \mathrm{~kg}$ \\
\hline Life expectancy & $8 \mathrm{~d}$ & $39 \mathrm{~d}$ & $66 \mathrm{~d}$ & $113 \mathrm{~d}$ & $191 \mathrm{~d}$ & $324 \mathrm{~d}$ \\
\hline
\end{tabular}

Table 5: Life history of an individual fish, for reference values of the parameters (table 2)

\subsection{Boundary conditions}

Equation (10) cannot be used for numerical computations : sizes have to be discretized, hence $x$ is bound in an interval $\left[x_{\min }, x_{\max }\right]$. Subsequently, equation (10) has no meaning because of the convolution integrals. To circumvent this difficulty, function $\varphi$ is truncated and the model is changed at both ends of the interval. In addition, an input of biomass to the system is needed. 


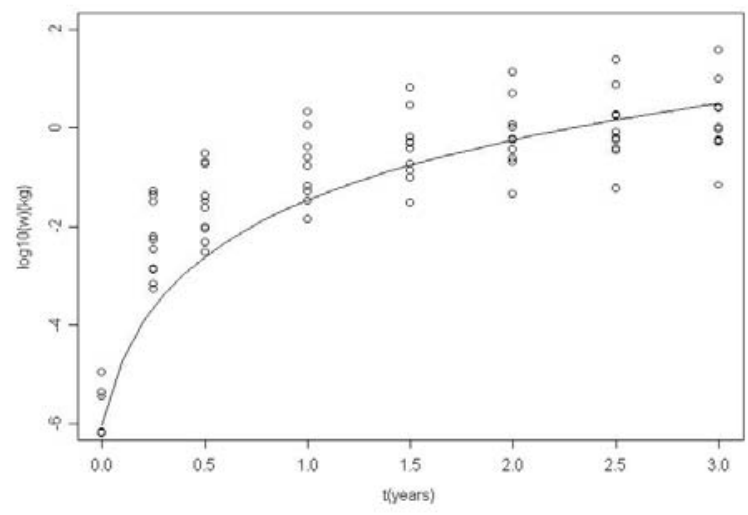

Figure 2: The model growth curve of an individual fish (line), compared with estimated weights at age derived from the data compiled by [Pauly, 1980] (circles) (For explanations see text).

In small size, the population of plankton $u_{p}(x, t)$ is assumed to control the system. In large size, the biomass should be almost independent of time. This is described by two simple models, the differential equation $\mathcal{B}$ for plankton, and $\mathcal{C}$ for very large animals.

$$
\begin{array}{rlll}
\frac{\partial u}{\partial t}=\mathcal{B}(u) & \text { where } & \mathcal{B}(u)=\frac{1}{\tau_{p}}\left(u_{p}-u\right) & \text { with } \tau_{p} \text { small } \\
\frac{\partial u}{\partial t}=\mathcal{C}(u) & \text { where } & \mathcal{C}(u)=\frac{1}{\tau_{m}}\left(u_{m}-u\right) & \text { with } \tau_{m} \text { large }
\end{array}
$$

The parameters $\tau_{p}$ (resp. $\tau_{m}$ ) is the characteristic time to return to equilibrium after a perturbation, for plankton (resp. large animals).

Call $\mathcal{A}$ the operator describing the dynamics in the fish size spectrum $u$ in equation (10):

$$
\begin{aligned}
\mathcal{A}(u)(x)= & -\frac{d}{d x}\left[K A e^{\alpha x} \int_{-\infty}^{\infty} e^{-q} \varphi(q) u(x-q) u(x) d q\right] \\
& -A e^{\alpha x} \int_{-\infty}^{\infty} e^{\alpha q} \varphi(q) u(x+q) u(x) d q \\
& -\mu_{0} e^{\alpha x} u(x, t)^{2}
\end{aligned}
$$

Models $\mathcal{B}$ and $\mathcal{C}$ were chosen similar to $\mathcal{A}$ to allow a smooth transition between the populations of plankton, fish and big fish. The complete model is then 
$\frac{\partial u}{\partial t}(x, t)=\psi_{p}(x) \psi_{m}(x) \mathcal{A}(u)(x)+\left(1-\psi_{p}(x)\right) \mathcal{B}(u, t)(x)+\left(1-\psi_{m}(x)\right) \mathcal{C}(u, t)(x)$

where $\psi_{p}$ and $\psi_{m}$ are smooth functions with:

$$
\left\{\begin{array} { l l } 
{ 0 \leq \psi _ { p } ( x ) \leq 1 } \\
{ \psi _ { p } ( x ) = 1 } \\
{ \psi _ { p } ( x ) = 0 } & { \text { for } \quad x > x _ { 2 } }
\end{array} \quad \left\{\begin{array}{ll}
0 \leq \psi_{m}(x) \leq 1 & \\
\psi_{m}(x)=1 & \text { for } \quad x<x_{1} \\
\psi_{m}(x)=0 & \text { for } \quad x>x_{3}
\end{array}\right.\right.
$$

The functions $\psi_{p}$ and $\psi_{m}$ used in simulations are cubic spline.

Hence the size spectrum governed by predation processes only is simulated in the size range $\left[x_{2}, x_{3}\right]$ only. For small sizes lower than $x_{1}$, model $\mathcal{B}$ is simulated, and model $\mathcal{C}$ for sizes larger than $x_{4}$. Over ranges $\left[x_{1}, x_{2}\right]$ and $\left[x_{3}, x_{4}\right]$ transition processes occur.

In addition, function $\varphi$ is truncated in simulations to ensure that $\varphi(q)=0$ while $q>x_{1}-x_{\min }$ and $q>x_{\max }-x_{4}$. This ensures that the composite operator in equation (13) is defined for all derivable functions over $\left[x_{\min }, x_{\max }\right]$.

\subsection{Fishing mortality}

For simulations, fishing mortality rate $\mu_{f}(x, t)$ is given by

$$
\mu_{f}(x, t)=\max (0, a(x-b))
$$

where $a$ and $b$ are parameters. It is a linearly increasing function of log weight with recruitment to fishing at weight $\exp (b)$. The parameters $a$ and $b$ were estimated by linear regression of fishing mortality rate $F$ at age versus log weight at age, combining all stocks assessed by the International Council for the Exploration of the Sea in i) the North Sea and ii) the Bay of Biscay. The resulting estimates did not to differ significantly (Table 6).

\subsection{Diffusion}

From a strictly mathematical view, equation (13) may not have a solution at any time $t$. At some time $t_{0}$, the slope of the size spectrum may become infinite in some point, then the solution would not be defined any more. This is well known for the Burgers equation $\partial u / \partial t=u \partial u / \partial x$. As a consequence, in some simulations, the population of fish of weight $e^{x_{0}}$ disappears at time $t_{0}$. 


\begin{tabular}{|c||l|c|c|l|}
\hline $\begin{array}{c}\text { Para- } \\
\text { meter }\end{array}$ & \multicolumn{1}{|c|}{ Definition } & Unit & $\begin{array}{l}\text { Ref. } \\
\text { value }\end{array}$ & \multicolumn{1}{|c|}{ Sources } \\
\hline \hline$b$ & $\begin{array}{l}\text { log weight at recruitment } \\
\text { to the fishery }\end{array}$ & - & $\ln (10)$ & $\begin{array}{l}\text { Estimated from } \\
\text { [Anonymous, 1998b, } \\
\text { Anonymous, 1998a] }\end{array}$ \\
\hline$a$ & $\begin{array}{l}\text { Slope of the fishing mor- } \\
\text { tality as a function of log } \\
\text { weight }\end{array}$ & $y^{-1}$ & 0.1 & $\begin{array}{l}\text { Estimated from } \\
\text { [Anonymous, 1998b, } \\
\text { Anonymous, 1998a] }\end{array}$ \\
\hline
\end{tabular}

Table 6: Values of the parameters of fishing mortality used in model simulations.

This problem was circumvented by introducing diffusion in the model. This amounts to assume that two fish of similar weight, eating the same prey, will not grow exactly by the same amount. Hence this will add realism to the model. Mathematically, this introduces an additional term $\partial^{2} u / \partial x^{2}$ in operator $\mathcal{A}$.

Simulated size spectra with non predation mortality $\left(\mu_{0}>0\right)$ are more regular than those without non predation mortality $\left(\mu_{0}=0\right)$. When $\mu_{0}>0$, diffusion is not needed to obtain a solution defined for all positive $t$. Unfortunately, we have no mathematical explanation for this observation.

\section{7 $\quad$ Simulated size spectra}

Size spectra were simulated following equation (13) using $\mathbf{C}^{++}$on a Personal Computer with an order 4 Runge-Kutta method and log weight $x$ discretized by an elementary method $(d x=d w / w=0.5)$. The size and time steps were determined by trial and error, small enough so that the observed patterns be independent of the value of the steps, and large enough to allow simulation of some years within a reasonable computing time. The process parameters were selected in table 2 and the boundary conditions parameters and limits are reported in table 7 .

\begin{tabular}{|}
\begin{tabular}{|r||c|c|c|c|c|c|}
\hline Parameter name & $w_{\min }$ & $w_{1}$ & $w_{2}$ & $w_{3}$ & $w_{4}$ & $w_{\max }$ \\
\hline Value & $10^{-12} \mathrm{~g}$ & $10^{-6} \mathrm{~g}$ & $10^{-3} \mathrm{~g}$ & $10^{6} \mathrm{~g}$ & $10^{9} \mathrm{~g}$ & $10^{12} \mathrm{~g}$ \\
\hline Parameter name & $\tau_{p}$ & $u_{p}(x, t)$ & $\tau_{m}$ & $u_{m}(x, t)$ \\
\hline Value & 10 days & $u_{0} e^{\lambda x}$ & 3 years & $u_{0} e^{\lambda x}$ \\
\hline
\end{tabular}
\end{tabular}

Table 7: Parameters and limits of the boundary conditions fixed for all simulations. (see section 5.4 for explanations)

A first series of simulations was run to check that the results conformed to 
the theoretical expectations. Linear spectra $u_{0} e^{\lambda x}$ were found to be stationary. A weaker slope initial spectrum decreased uniformly for all weights, conforming to section 3.3.1. For $\mu_{0}=0$, an initial spectrum with appropriate gaps was stationary, conforming to section 3.3.2 as well.

Further simulations were run i) to study the stability of the stationary solution and ii) to predict the effect of fishing on the stationary solution (Fig. $3)$.

When the initial spectrum is perturbed by a sine function around the stationary slope, the peaks move downwards the spectrum and are rapidly damped, especially in small sizes (Fig. 3.a). On the other hand, if the plankton input to the spectrum oscillates in time following a sine function, the oscillations expand while propagating through the spectrum (Fig. 3.b) and may result in infinite values if their amplitude is too large. This confirms a conjecture of [Silvert and Platt, 1980] that small oscillations in the food supply can drive large swings in populations. Note that the amplitude of the perturbations added is very large as the figures span 14 orders of magnitude (from $10^{-10}$ to $10^{+4}$ ) on the $y$-axis. Introducing either diffusion or larger non predation mortality stabilises the solution (not shown). A strong fishing mortality results in a steeper slope of the stationary solution in larger sizes. Introducing fishing mortality starting at weight $1 \mathrm{~g}$ causes a change in slope for weights larger than $10 \mathrm{~kg}$ (Fig. 3.c). However, a more realistic fishing mortality (as estimated from the North Sea and Bay of Biscay stocks) has no apparent effect on the slope of the spectrum, but rather on its curvature (Fig. 3.d). This effect is not larger than the oscillations created by perturbations added to the model, which can have a fairly large amplitude (Fig. 3.e and f).

\section{Discussion}

That a regular size spectrum can be the result of regularity in the predation processes along the food web was suspected by [Beyer, 1989], who found that if the size spectrum is linear and if growth and mortality rates are allometric, then mortality rate has to be proportional to growth rate (ie, they should have the same allometric exponent). [Silvert and Platt, 1980] formally started from the processes to prove that given allometric growth and mortality and a constant predator to prey size ratio, a linear size spectrum is stationary. In an unpublished paper, Beyer further proved that his result is still valid when predators select their preys according to a log-normal (symmetric) suitability rather than 
a single size (J. Beyer, 1990. Size spectrum theory and multispecies assessment: basic concepts and perspectives. Working paper No 21 to the ICES Multispecies Working Group hold in Woods Hole, dec. 1990). The present study still relaxes this assumption and proves that a linear spectrum can be stationary for any distribution of prey size suitability, provided this distribution is consistent throughout the whole size spectrum. This is an important contribution as field data show that there is a wide variability in predator to prey size ratio, and that predator size - prey size distributions are asymmetric [Scharf et al., 2000]. Furthermore, we demonstrate that a linear spectrum is still possible while taking account of non predation mortality, provided the latter has an appropriate allometric exponent. Thus improving the realism of the assumptions does not necessarily increase the complexity of the solution.

Under the same assumptions, size spectra can also be oscillating, both in time and along the size axis. Perturbations that are likely to occur in the real world, such as seasonal primary production, can result in oscillations in the spectrum. Size spectra observed from various marine communities frequently show oscillations [Pope and Knights, 1982, Murawski and Idoine, 1992, Drgas et al., 1998, Saiz-Salinas and Ramos, 1999, Rochet and Lembo, 2003]. On the other hand, solutions oscillating in size can also be stationary. This has to do with the "multispectrum" theory developed by [Dickie et al., 1987, Boudreau et al., 1991]. They assumed discrete jumps of energy between relatively fixed size ranges of prey and predator, resulting in a secondary structure of the body size spectrum consisting of a series of stationary biomass domes periodically spaced. The data from several ecosystems verify this theory (see review of theory and data in [Kerr and Dickie, 2001]). Our results show that there is no need to assume discrete trophic levels to obtain periodic spectra.

Although assuming a variable rather than fixed predator to prey size ratio improves the regularity of the size spectrum model, it is still unstable. Simulations frequently resulted in ecosystem crash and this is justified theoretically (see section 5.6). However, introducing diffusion in the model stabilised the solution: once again, the more realistic assumption that all fish are not similar but have a variable efficiency in food assimilation improves the realism of the solution. Moreover, this is a contribution to the never-ended debate about biodiversity and ecosystem stability [Johnson et al., 1996]. In this model, introducing biodiversity (although a small amount of it) improves the stability of the system. Surprisingly, the non predation mortality term also improves the stability of the solution. This may be due to the density-dependence introduced 
thereby, providing a week feedback control of numbers in the spectrum.

Introducing a simple size-dependent fishing mortality results in a steeper slope of the spectrum, as inferred a long time ago by fisheries scientists. This change of slope occurs in a range of sizes larger than the size at recruitment. Given the parametrisation of the model in the present study, a realistic fishing mortality as estimated from the North Sea and Bay of Biscay does not result in a change in the slope of the spectrum. Rather, its curvature and regularity are affected by fishing. These impacts are expected to be larger if diffusion and oscillations in primary production are assumed. Moreover, it might be underestimated in the simulations, due to assuming a process that keeps the biomass invariant in large sizes (section 5.4). Hence we conclude that realistic fishing pressures could cause disruptions in the size spectrum, consistently with the increasing awareness that fishing depletes large predators in world fisheries [Myers and Worm, 2003, Pauly et al., 1998].

Our result differs from the study by Gislason and Rice [Gislason and Rice, 1998] who predicted, based on a Multi Species Virtual Population Analysis (MSVPA) model, that the change in slope of the size spectrum in the North Sea would be proportional to the change in fishing intensity by a factor of -1.3 to -3 . This might be due to the completely different structures of the models. MSVPA describes the age-structured dynamics of a few commercial species; the less well known remainder of the food web is fixed. Hence compensations and species replacements in diets assumed to occur in any case in the present model are completely neglected in MSVPA. This hypothesis is confirmed by the results by [Shin and Cury, ress]. These authors developed a multispecies individual-based model where predation is a size-based opportunistic process. Their simulations show that fishing impacts the slope of the size spectrum if it is assumed linear, and its curvature if it is assumed quadratic. This would explain why published evidences of fishing effects on the slope of size spectra are not consistent (see review in [Rochet and Trenkel, 2003]). If, as shown by our work, the main effects of fishing on size spectra are to increase their curvature and to make them vary through time, the linearity assumption would result in erroneous and variable slope estimates that would not be straightforward to interpret. This would be an argument not to use the slope of size spectra, but rather some other characteristic, if we are to monitor fishing impacts.

The main predicted effect of a realistic fishing pressure in the present model is to increase oscillations in the size spectrum in large sizes. These oscillations 
are caused by the depletion of large fish, allowing the numbers in the lower size-classes to increase due to decreased predation. These increased numbers in turn exert an increased predation on the next lower size-classes, and so on. These effects then propagate backwards to large sizes as a depleted size class will cause food scarcity for the next larger size class. Indeed, many published size spectra from exploited fish communities show oscillations, but a comparison of the magnitude of these oscillations with less exploited communities or with the predictions of the model would hardly be feasible. An interesting feature of this model is that controls occur both top-down (predators controlling prey numbers) and bottom-up (preys limiting predator growth) and in this way may reflect the complexity of real food webs.

\section{Acknowledgements}

This study was initiated during meetings of the research group GDR 1107 " Outils et modèles de l'automatique dans l'étude de la dynamique des écosystèmes et du contrôle des ressources renouvelables " funded by the Centre National de la Recherche Scientifique. We thank two anonymous referees for useful comments on an earlier version of this manuscript.

\section{References}

[Andersen and Ursin, 1977] Andersen, K. P. and Ursin, E. (1977). A multispecies extension to the Beverton and Holt theory of fishing, with accounts of phosphorus circulation and primary production. Meddelelser fra Danmarks Fiskeri- og Havundersøgelser, VII:319-435.

[Anonymous, 1995] Report of the Working Group on Ecosystem effects of fishing activities. ICES Cooperative Research Report 200, ICES.

[Anonymous, 1996] Report of the Working Group on Ecosystem effects of fishing activities. ICES C.M. 1996 / Assess / Env: 1.

[Anonymous, 1998a] Report of the working group on the assessment of demersal stocks in the North Sea and Skagerrak. ICES C.M. Assess: 7.

[Anonymous, 1998b] Report of the working group on the assessment of Southern Shelf demersal stocks. ICES C.M. Assess: 4. 
[Anonymous, 2002] Report of the workshop on MSVPA in the North Sea. Technical Report ICES C.M. 2002 / D: 04, ICES.

[Beyer, 1989] Beyer, J. E. (1989). Recruitment stability and survival - simple size-specific theory with examples from the early life dynamics of marine fish. Dana, $7: 45-147$.

[Bianchi et al., 2000] Bianchi, G., Gislason, H., Graham, K., Hill, L., Jin, X., Koranteng, K., Manickchand-Heileman, S., Payá, I., Sainsbury, K., Sanchez, F., and Zwanenburg, K. (2000). Impact of fishing on size composition and diversity of demersal fish communities. ICES J. mar. Sci., 57:558-571.

[Borgman, 1982] Borgman, U. (1982). Particle-size-conversion efficiency and total animal production in pelagic ecosystems. Can. J. Fish. Aquat. Sci., $39: 668-674$.

[Borgman, 1983] Borgman, U. (1983). Effect of somatic growth and reproduction on biomass transfer up pelagic food webs as calculated from particle-size conversion efficiency. Can. J. Fish. Aquat. Sci., 40:2010-2018.

[Borgman and Whittle, 1983] Borgman, U. and Whittle, D. M. (1983). Particlesize-conversion efficiency and contaminant concentrations in Lake Ontario biota. Can. J. Fish. Aquat. Sci., 40:328-336.

[Boudreau and Dickie, 1992] Boudreau, P. R. and Dickie, L. M. (1992). Biomass spectra of aquatic ecosystems in relation to fisheries yield. Canadian Journal of Fisheries and Aquatic Sciences, 49:1528-1538.

[Boudreau et al., 1991] Boudreau, P. R., Dickie, L. M., and Kerr, S. R. (1991). Body-size spectra of production and biomass as system-level indicators of ecological dynamics. J. theor. Biol., 152:329-339.

[Buckel et al., 1995] Buckel, J. A., Steinberg, N. D., and Conover, D. O. (1995). Effects of temperature, salinity, and fish size on growth and consumption of juvenile bluefish. Journal of Fish Biology, 47:696-706.

[Caddy and Mahon, 1996] Caddy, J. F. and Mahon, R. (1996). Reference points for fisheries management, volume 347 of FAO Fisheries Technical Paper. FAO. 
[Cohen et al., 1993] Cohen, J. E., Pimm, S. L., Yodzis, P., and Saldana, J. (1993). Body sizes of animal predators and animal prey in food webs. Journal of Animal Ecology, 62:67-78.

[Cottingham, 1999] Cottingham, K. L. (1999). Nutrients and zooplankton as multiple stressors of phytoplancton communities: evidence from size structure. Limnol. Oceanogr., 44(3):810-827.

[Cyr and Peters, 1996] Cyr, H. and Peters, R. H. (1996). Biomass-size spectra and the prediction of fish biomass in lakes. Can. J. Fish. Aquat. Sci., 53:9941006.

[Daan, 1973] Daan, N. (1973). A quantitative analysis of the food intake of North Sea cod, Gadus morhua. Netherlands Journal of Sea Research, $6(4): 479-517$.

[Denman et al., 1989] Denman, K. L., Freeland, H. J., and Mackas, D. L. (1989). Comparisons of time scales for biomass transfer up the marine food web and coastal transport processes. Can. Spec. Publ. Fish. Aquat. Sci., 108:255-264.

[Dickie et al., 1987] Dickie, L. M., Kerr, S. R., and Boudreau, P. R. (1987). Sizedependent processes underlying regularities in ecosystem structure.Ecological Monographs, 57(3):233-250.

[Drgas et al., 1998] Drgas, A., Radziejewska, T., and Warzocha, J. (1998). Biomass size spectra of near-shore shallow-water benthic communities in the Gulf of Gdansk (Southern Baltic Sea). Marine Ecology, 19(3):209-228.

[Essington et al., 2001] Essington, T. E., Kitchell, J. F., and Walters, C. J. (2001). The von Bertalanffy growth function, bioenergetics, and the consumption rates of fish. Can. J. Fish. Aquat. Sci., 58:2129-2138.

[Gislason, 1999] Gislason, H. (1999). Single and multispecies reference points for Baltic fish stocks. ICES J. mar. Sci., 56:571-583.

[Gislason and Helgason, 1985] Gislason, H. and Helgason, T. (1985). Species interaction in assessment of fish stocks with special application to the North Sea. Dana, 5(2):1-44. 
[Gislason and Rice, 1998] Gislason, H. and Rice, J. (1998). Modelling the response of size and diversity spectra of fish assemblages to changes in exploitation. ICES Journal of Marine Science, 55:362-370.

[Greenstreet and Hall, 1996] Greenstreet, S. P. R. and Hall, S. J. (1996). Fishing and the ground-fish assemblage structure in the north-western North Sea: an analysis of long-term and spatial trends. Journal of Animal Ecology, 65:577-598.

[Gurney et al., 1990] Gurney, W. S. C., McCauley, E., Nisbet, R. M., and Murdoch, W. W. (1990). The physiological ecology of Daphnia: a dynamic model of growth and reproduction. Ecology, 71(2):716-732.

[Johnson et al., 1996] Johnson, K. H., Vogt, K. A., Clark, H. J., Schmitz, O. J., and Vogt, D. J. (1996). Biodiversity and the productivity and stability of ecosystems. TREE, 11:372-377.

[Kerr, 1974] Kerr, S. R. (1974). Theory of size distribution in ecological communities. Journal of the Fisheries Research Board of Canada, 31:1859-1862.

[Kerr and Dickie, 2001] Kerr, S. R. and Dickie, L. M. (2001). The biomass spectrum. A predator-prey theory of aquatic production, volume 8 of Complexity in ecological systems series. Columbia University Press.

[Kot, 2001] Kot, M. (2001). Elements of mathematical ecology Cambridge University Press.

[Leach et al., 1987] Leach, J. H., Dickie, L. M., Shuter, B. J., Borgman, U., Hyman, J., and Lysack, W. (1987). A review of methods for prediction of potential fish production with application to the Great Lakes and Lake Winnipeg. Can. J. Fish. Aquat. Sci., 44 (Suppl. 2):471-485.

[Macpherson and Gordoa, 1996] Macpherson, E. and Gordoa, A. (1996). Biomass spectra in benthic fish assemblages in the Benguela system. $M a-$ rine Ecology Progress Series, 138:27-32.

[Murawski and Idoine, 1992] Murawski, S. A. and Idoine, J. S. (1992). Multispecies size composition: a conservative property of exploited fishery systems? J. Northw. Atl. Fish. Sci., 14:79-85.

[Myers and Worm, 2003] Myers, R. A. and Worm, B. (2003). Rapid worldwide depletion of predatory fish communities. Nature, 423(15 May 2003):280-283. 
[Paloheimo and Dickie, 1966] Paloheimo, J. E. and Dickie, L. M. (1966). Food and growth of fishes. III. Relations among food, body size, and growth efficiency. J. Fish. Res. Bd. Canada, 23(8):1209-1248.

[Pauly, 1980] Pauly, D. (1980). On the interrelationships between natural mortality, growth parameters, and mean environmental temperature in 175 fish stocks. Journal du Conseil International pour l'Exploration de la Mer, 39:175192.

[Pauly et al., 1998] Pauly, D., Christensen, V., Dalsgaard, J., Froese, R., and Torres, F. J. (1998). Fishing down marine food webs. Science, 279:860-863.

[Pepin and Penney, 2000] Pepin, P. and Penney, R. (2000). Feeding by a larval fish community: impact on zooplankton. Marine Ecology Progress Series, 204:199-212.

[Peterson and Wroblewski, 1984] Peterson, I. and Wroblewski, J. S. (1984). Mortality rate of fishes in the pelagic ecosystem. Can. J. Fish. Aquat. Sci., 41:1117-1120.

[Platt and Denman, 1978] Platt, T. and Denman, K. (1978). The structure of pelagic marine ecosystems. Rapp. P.-v. Réun. Cons. int. Explor. Mer, 173:60-65.

[Pope and Knights, 1982] Pope, J. G. and Knights, B. J. (1982). Comparison of length distributions of combined catches of all demersal fishes in surveys in the North Sea and at Faroe Bank. In: Multispecies approaches to fisheries management advice. M.C. Mercer (Ed.), Can. Spec. Publ. Fish. Aquat. Sci, $59: 116-118$.

[Pope et al., 1988] Pope, J. G., Stokes, T. K., Murawski, S. A., and Idoine, S. I. (1988). A comparison of fish size composition in the North Sea and on Georges Bank. In Wolff, W., Soeder, C., and Drepper, F., editors, Ecodynamics, contributions of theoretical ecology, pages 146-152. Springer-Verlag.

[Rice and Gislason, 1996] Rice, J. and Gislason, H. (1996). Patterns of change in the size spectra of numbers and diversity of the North Sea fish assemblage, as reflected in surveys and models. ICES Journal of Marine Science, 53:12141225 .

[Rochet and Lembo, 2003] Rochet, M. J. and Lembo, G. (2003). Multispecies size spectra analysis in the Mediterranean. Submitted. 
[Rochet and Trenkel, 2003] Rochet, M. J. and Trenkel, V. M. (2003). Which community indicators can measure the impact of fishing? a review and proposals. Canadian Journal of Fisheries and Aquatic Sciences, 60:86-99.

[Saiz-Salinas and Ramos, 1999] Saiz-Salinas, J. I. and Ramos, A. (1999). Biomass size-spectra of macrobenthic assemblages along water depth in Antarctica. Marine Ecology Progress Series, 178:221-227.

[Scharf et al., 2000] Scharf, F. S., Juanes, F., and Rountree, R. A. (2000). Predator size - prey size relationships of marine fish predators: interspecific variation and effects of ontogeny and body size on trophic-niche breadth. Marine Ecology Progress Series, 208:229-248.

[Schwinghamer, 1981] Schwinghamer, P. (1981). Characteristic size distributions of integral benthic communities. Canadian Journal of Fisheries and Aquatic Sciences, 38:1255-1263.

[Sheldon et al., 1972] Sheldon, R. W., Prakash, A., and Sutcliffe, W. H. J. (1972). The size distribution of particles in the ocean. Limnol. Oceanogr., $17(3): 327-340$.

[Sheldon et al., 1977] Sheldon, R. W., Sutcliffe, W. H., and Paranjape, M. A. (1977). Structure of pelagic food chain and relationship between plankton and fish production. J. Fish. Res. Board Can., 34:2344-2353.

[Shin and Cury, ress] Shin, Y.-J. and Cury, P. (in press). Using an individualbased model of fish assemblages to study the response of size spectra to changes in fishing. Canadian Journal of Fisheries and Aquatic Sciences

[Silvert and Platt, 1978] Silvert, W. and Platt, T. (1978). Energy flux in the pelagic ecosystem: a time-dependent equation. Limnol. Oceanogr., 23(4):813816.

[Silvert and Platt, 1980] Silvert, W. and Platt, T. (1980). Dynamic energy flow model of the particle size distribution in pelagic ecosystems. In Kerfoot, W., editor, Evolution and ecology of zooplancton communities pages 754-763. University Press of New England.

[Sprules et al., 1991] Sprules, W. G., Brandt, S. B., Stewart, D. J., Munawar, M., Jin, E. H., and Love, J. (1991). Biomass size spectrum of the lake Michigan pelagic food web. Can. J. Fish. Aquat. Sci., 48:105-115. 
[Sprules and Munawar, 1986] Sprules, W. G. and Munawar, M. (1986). Plankton size spectra in relation to ecosystem productivity, size, and perturbation. Can. J. Fish. Aquat. Sci., 43:1789-1794.

[Thiebaux and Dickie, 1992] Thiebaux, M. L. and Dickie, L. M. (1992). Models of aquatic biomass size spectra and the common structure of their solutions. J. theor. Biol., 159:147-161.

[Thiebaux and Dickie, 1993] Thiebaux, M. L. and Dickie, L. M. (1993). Structure of the body-size spectrum of the biomass in aquatic ecosystems: a consequence of allometry in predator-prey interactions. Can. J. Fish. Aquat. Sci., 50:1308-1317.

[Vignes, 1998] Vignes, J.-C. (1998). Relations entre la taille des juvéniles de saumon atlantique (Salmo salar) et certaines caractéristiques de leurs proies. Cybium, 22(1):49-56.

[Ware, 1978] Ware, D. M. (1978). Bioenergetics of pelagic fish: theoretical change in swimming speed and ration with body size. Journal of the Fishery Research Board of Canada, 35:220-228.

[Zhou and Huntley, 1997] Zhou, M. and Huntley, M. E. (1997). Population dynamics theory of plankton based on biomass spectra. Marine Ecology Progress Series, 159:61-73.

\begin{tabular}{|c||c|c|c|c|c|c|c|}
\hline Panel & $\begin{array}{c}\text { First } \\
\text { time } \\
\text { plotted } \\
\text { (y) }\end{array}$ & $\begin{array}{c}\text { Last } \\
\text { time } \\
\text { plotted } \\
(\mathrm{y})\end{array}$ & $\begin{array}{c}\text { Time } \\
\text { step }\end{array}$ & $\begin{array}{c}\text { Initial } \\
\text { condition }\end{array}$ & $\begin{array}{c}\text { Left boundary } \\
\text { condition }\end{array}$ & \multicolumn{2}{|c|}{$\begin{array}{c}\text { Fishing } \\
\text { mortality } \\
\text { parameters }\end{array}$} \\
\hline a) & 0 & 3 & 2 & $u_{0} e^{\lambda x}(1+\sin x)$ & $u_{0} e^{\lambda x}$ & 0 & 0 \\
\hline b) & 0 & 3 & 2 & $u_{0} e^{\lambda x}$ & $u_{0} e^{\lambda x}(1+0.3 \sin (2 \pi t))$ & 0 & 0 \\
\hline c) & 10 & 15 & 3 & $u_{0} e^{\lambda x}$ & $u_{0} e^{\lambda x}$ & 0.5 & $\log 1$ \\
\hline d) & 10 & 15 & 3 & $u_{0} e^{\lambda x}$ & $u_{0} e^{\lambda x}$ & 0.1 & $\log 10$ \\
\hline e)f $)$ & 10 & 15 & 3 & $u_{0} e^{\lambda x}(1+\sin x)$ & $u_{0} e^{\lambda x}(1+0.3 \sin (2 \pi t))$ & 0.1 & $\log 10$ \\
\hline
\end{tabular}

Table 8: Parameters for the simulations plotted in figure 3. 
Figure 3: Simulated size spectra using reference parameters of Tables 2 and 7, unless otherwise specified in table 8 .

The dynamics of the spectrum is represented by plotting the model solution for successive steps $d t, 2 d t, \ldots, N d t$ with a grey shading from white at $d t$ to black at $N d t$.

Dashed line: initial condition.

Gray bold line : stationary solution.

a) Oscillatory initial spectrum.

b) Oscillatory plankton input.

c) Strong fishing effort.

d) Realistic fishing effort.

e) Realistic fishing effort with oscillatory initial condition and oscillatory plankton input.

f) The same as e) focused on a fish-like size range.

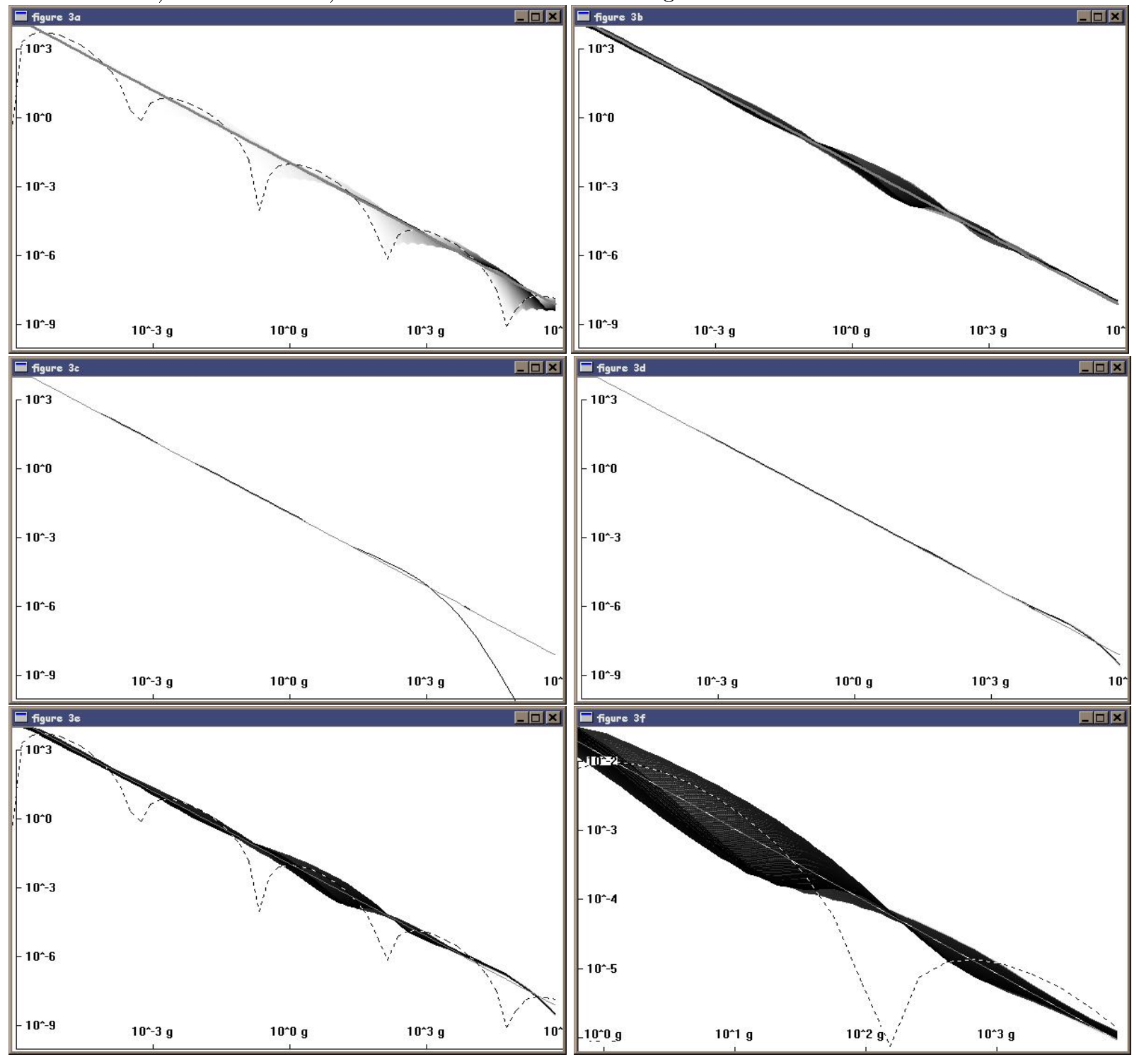

